\title{
LA OBJECIÓN DE LA IGNORANCIA PÚBLICA
}

\author{
Ubaldo A. Suárez Acosta \\ Universidad Nacional de Educación a Distancia (UNED)
}

http://dx.doi.org/10.5209/NOMA.53298

\begin{abstract}
Resumen: Las teorías deliberativas de la democracia han pasado de cuestionar en su totalidad los sistemas democráticos representativos y sus procedimientos de toma de decisiones a buscar su posibilidad de realización acomodándose a las instituciones liberales. Sin embargo, la deliberación democrática sigue suscitando oposición entre varios autores por varias razones, una de las cuales, especialmente conspicua, es la llamada objeción de la ignorancia pública, que afirma que el público por su ignorancia de los asuntos políticos está incapacitado para cumplir las exigentes requisitos que toda deliberación política presupone y por la que esta, a gran escala, deviene indeseable, cuando no imposible.
\end{abstract}

Palabras clave: Objeción de la ignorancia pública, giro deliberativo, democracia deliberativa, democracia liberal.

Abstract: Deliberative theories of Democracy have moved away from the radical criticism of liberal democracy and their procedures to the feasibility of deliberation in the liberal institutions. However, deliberative theory keeps finding opposition between some authors for several reasons, being one of the most conspicuous the so called Public Ignorance Objection. This objection affirms that public is ignorant of political matters and that is why is unable to satisfy the requisites for actual deliberation. That renders political mass deliberation undesirable, if not impossible.

Keywords: Public Ignorance Objection, deliberative turn, deliberative democracy, liberal democracy.

\section{Introducción}

Al igual que otros giros en Filosofía como el lingüístico o el pragmático, existe también en la filosofía política un giro deliberativo (Dryzek, 2000, pp. 1-8). John S. Dryzek lo sitúa en la década final del siglo XX, aunque sus antecesores datan de mucho antes (John Dewey y Hannah Arendt, por ejemplo, y anteriormente en J.S. Mill o, claro está, en la polis griega).

En una primera época, los autores deliberativos abjuraban de la consideración de la voluntad popular como un simple agregado de votos que reflejaban meramente el interés propio de cada votante: la metáfora del mercado. El voto (aunque en última instancia se recurra a él) es desplazado por la discusión/conversación; el consentimiento, por la pública rendición de cuentas. Las preferencias fijadas de antemano se sustituyen por procesos formativos de la voluntad durante la deliberación. El regateo, por los argumentos. Es decir, era una enmienda conceptual casi a la totalidad a los mecanismos representativos de la democracia liberal. 
Sin embargo, en una segunda época, y tal y como señalan James Bohman o Simone Chambers, entre otros, las reflexiones sobre la democracia deliberativa han pasado de considerar a ésta como antagonista de la versión representativa y a sus instituciones a adoptar una postura por la que se pretende adaptar estas últimas a esa visión deliberativa, considerándolas válidas para seguir democratizando tanto al Estado como a la sociedad. Así, en los últimos tiempos se ha pasado del esfuerzo teórico de definir lo que es o no la democracia deliberativa a considerar cómo se implementa o puede implementarse ${ }^{1}$. Es decir, los esfuerzos teóricos se encaminan a implementar herramientas deliberativas en el seno de las democracias liberales y de sus instituciones coexistiendo con otras herramientas propias de éstas como el voto, de carácter agregativo; o la negociación, de carácter estratégico. El énfasis no se hace tanto en el consenso como en la aceptación del resultado de la deliberación y el voto siempre que hayan llevado a cabo mediante procedimientos deliberativos inclusivos. Las constricciones de tiempo, espacio y número que son las que impulsaron el modelo representativo siguen siendo igual de apremiantes para los defensores de la democracia deliberativa, por lo que la transición a teorizaciones menos puras surge como necesidad de dar respuesta a situaciones políticas reales, primando pues la reflexión empírica en contraste con la elaboración de situaciones ideales de carácter normativo. A este respecto, Bohman señala:

Como una versión factible de la democracia participativa, las teorías de la democracia deliberativa han ido, cada vez más, pasando de cuestiones de justificación a problemas de diseño institucional. (...) Muchos de los rasgos de la democracia como ésta se ha ido desarrollando (voto, la revisión judicial (control constitucional), el constitucionalismo, la representación, el saber experto) ya no se rechazan 0 se identifican como "meramente agregativa", sino que son reinterpretados con el fin de promover el ideal deliberativo. ${ }^{2}$ (Bohman, 1998, p. 415).

Lo que habría de plantearse de esta nueva fase más pragmática es si supone un esfuerzo de teorización encaminado a optimizar las posibilidades deliberativas y, en cierta relación, más democratizadoras que se supone que comportan o si podemos considerarla como una claudicación en la aspiración a cambiar las relaciones de poder en las sociedades occidentales donde este debate ha tenido mayor desarrollo. Este acomodamiento a las instituciones liberales podría significar una prórroga (en el caso de que estas reformas deliberativas tuviesen buena acogida) en la legitimación de las estructuras liberales en lo político y capitalistas en lo económico. Esto podría no ser problemático si lo que se pretende es la mera estabilidad del sistema, claro está. Bohman (1998, p. 423), al respecto, nos advierte de que no tenemos por qué situarnos ante lo que considera una falso dilema. La factibilidad de la deliberación "no implica ni la renuncia a los ideales originales de la democracia deliberativa ni la mera adaptación a los hechos sociales e institucionales existentes".

En este punto, nos hacemos eco de las palabras de la filósofa J.L. Cohen (1999, p. 216): "La génesis deliberativa y la justificación de políticas o decisiones públicas que

1 Cf. CHAMBERS, S. Deliberative Democratic Theory. Annual Reviews of Political Science: 6, 2003, págs. 307-326 y BOHMAN, J. The Coming of Age of Deliberative Democracy. The Journal of Political Philosophy: Volume 6, Number 4, 1998, págs. 400-425.

2 Traducción propia de la bibliografía en lengua inglesa. 
afecten al público en espacios públicos civiles y políticos respectivamente deben ser vistos como constitutivos de la forma moderna de democracia". Es decir, ya no es posible pensar en la oposición entre sistemas democrático-representativos y formas más deliberativas y participativas, sino como institucionalizar la deliberación y participación ciudadanas que sean vinculantes a la toma de decisiones por el poder político.

\section{La objeción de la ignorancia pública}

Sin embargo hay pensadores que contemplan las teorías deliberativas con pesimismo (y las que promueven mayor participación ciudadana, en general) atendiendo a la ignorancia, incompetencia o apatía de la ciudadanía. Es la llamada objeción de la ignorancia pública (the Public Ignorance Objection), cuyo ilustre antecesor es Platón (con su metáfora del piloto de la nave). Más recientemente, Joseph A. Schumpeter es el epígono más conocido en el siglo $\mathrm{XX}$, quien no sólo niega la existencia de una voluntad general, algo con lo que se puede estar de acuerdo, siempre y cuando se trate de un ente metafísico que haya que descubrir y no un acuerdo que se pueda construir, sino que su concepción de la naturaleza humana en política es pesimista, por decirlo de manera amable:

El reducido sentido de la responsabilidad y la ausencia de volición efectiva explican respectivamente la ignorancia y la falta de juicio del ciudadano corriente en asuntos de política interior y exterior, lo que es aún más sorprendente en el caso de personas que en asuntos no políticos disfrutan de éxito que en gente más humilde y sin estudios. Existe disponible abundante información, pero esto no parece marcar diferencia alguna. (Schumpeter, 1994, p. 260)

La falta de interés por asuntos que vayan más allá del espacio que ocupen los asuntos privados familiares o laborales, la falta de racionalidad con la que se abordan los asuntos políticos hace que Schumpeter (1994, p. 262) continúe del siguiente modo:

Así, el ciudadano típico cae a un nivel inferior de actividad mental desde que entra en la esfera de los asuntos políticos. Discute y analiza de un modo que él mismo reconocería como infantil si lo hiciera respecto de sus intereses reales. Se vuelve un ser primitivo de nuevo.

Con sus propias matizaciones, esta objeción de la ignorancia del ciudadano común es asimismo esgrimida por autores como Richard Posner, llya Somin, Giovanni Sartori y, en nuestro país, Manuel Arias Maldonado, quien afirma:

La mayoría de los ciudadanos no parece tener el grado de interés que requiere el modelo deliberativo, ni se muestra inclinada a adquirir la cantidad de información necesaria para poder formarse juicios de valor mínimamente sofisticados acerca de los asuntos públicos. (Arias, 2012, p. 79)

Una opinión pública de calidad si ya es necesaria para la democracia representativa tanto más lo es para la deliberativa. Tanto Arias Maldonado, para el caso español, como Somin, para los EE.UU. hacen uso de varias estadísticas que demuestran la extrema pobreza de información política que posee gran parte de la ciudadanía. 
Somin (1998, p. 418) señala que dicha ignorancia se manifiesta en tres aspectos, a saber: 1) Desconocimiento de la estructura y funcionamiento del gobierno; 2) carencia de una visión ideológica de la política, con la que integrar diversos asuntos en un marco abarcador; y 3) incapacidad (comparativamente hablando) de detectar relaciones entre asuntos políticos. Ante ello, los atajos cognitivos como la información que se recoge en la vida diaria los flujos de información provenientes de los partidos políticos, la opinión de los líderes de opinión o el voto retrospectivo no resultan, en su opinión, de demasiada ayuda.

Sin embargo, la ignorancia, digamos, masiva se ve agravada por la ignorancia de las élites. Esta ignorancia es inevitable dado el tamaño que ha alcanzado el Estado (Somin habla de los Estados Unidos, pero bien puede extrapolarse el ejemplo a cualquier país occidental) y la creciente extensión y complejidad de los asuntos de los que se encarga. "Es improbable que ni siquiera los científicos sociales posean más que un conocimiento superficial de las actividades de las agencias del gobierno fuera del campo de su especialidad, si es que alguna vez han oído hablar de ellas" (Somin, 1998, p. 432).

Ante este incremento de la dificultad, como quiera que se entienda, y del número de los asuntos de los que debe encargarse el Estado, es imposible que los ciudadanos puedan reflexionar y opinar cabalmente sobre políticas gubernamentales concretas. Su opinión se resume en la fórmula: "El control democrático del gobierno puede que se incremente cuando hay menos gobierno que controlar" (Somin, 1998, p. 435).

Por su parte, Arias Maldonado (2007, p. 51) concede, a lo sumo, a las teorías deliberativas de la democracia la de convertirse en una piedra de toque en contacto con la cual afinar la actual democracia representativa. Achaca a aquellas teorías su insistencia en fijar en su centro a un ciudadano (medio) que no existe. Según este autor, las exigentes capacidades que se requieren para poder participar en debates deliberativos están ausentes en la mayoría de la ciudadanía. Así pues, la opinión pública, en este caso, la española "desconoce mayoritariamente los asuntos sobre los que se trata y decide" (Arias, 2012, pp. 80-81) y alude a datos que muestran los escasos índices de lectura de la sociedad y los compara con el gasto creciente en juegos de azar. Arias valora de manera positiva, sin embargo, la posibilidad de que cierta sabiduría colectiva emerja con Internet por poseer aquellas características que se asemejan a la mano invisible del mercado:

Se trata de un tipo de participación ciudadana que combina elementos deliberativos con otros cooperativos, pero que también remite a las cualidades epistemológicas del mercado, por tratarse de espacios descentralizados donde el contacto con los demás es relativamente impersonal (dado el anonimato) y diferido (porque el diálogo directo no es habitual). (Arias, 2012, p. 83)

Por otro lado, no deja de ser falaz como argumento la comparación entre bajos índices de lectura e incremento en la participación de juegos de azar, pues nada indica que ambas actividades sean incompatibles o tengan alguna relación de causalidad.

En relación con las tesis de los autores citados, ya el jurista norteamericano Richard Posner (2004) había puesto de relieve con cierta acidez la supuesta apatía de los 
ciudadanos norteamericanos para interesarse por la política, en referencia a los sondeos deliberativos de Fishkin y a su Deliberation Day: "A la democracia no le hace falta un día de la deliberación. Si los votantes consideraran que vale la pena gastar un día en discutir esos asuntos, no habría necesidad de pagarles". En el fondo, su tesis es que a los ciudadanos no les interesa la política, ni falta que les hace, pues prefieren dedicarse a sus actividades privadas. En todo caso, si tal deliberación ciudadana se produjera a gran escala sólo acarrearía consecuencias negativas, "Puede esperarse, de modo razonable, que la deliberación arroje luz sobre la interacción humana, pero esto puede que revele diferencias que estaban escondidas, al igual que motivos escondidos para la convergencia. Todo depende de las intereses subyacentes que están en juego" (Shapiro, 2002).

Esto último está en la línea de lo que Cass Sunstein (2001, p. 15) denomina group polarization: "Los miembros de un grupo deliberante se mueven de manera predecible hacia un punto más extremo en la dirección indicada por las tendencias predeliberativas de los miembros". Es decir, que los miembros de un grupo, tras la deliberación, se moverán hacia un punto más extremo respecto de su posición inicial. Sunstein señala que la polarización muestra así que la deliberación no es siempre buena por sí misma.

Así pues, Posner da el paso de la ignorancia al desinterés, que no son lo mismo. No obstante, dicho desinterés por la política también probaría la futilidad de las teorías deliberativas.

En la misma línea, Somin (1998, p. 436) considera, citando a Downs, que el desinterés ciudadano se explica por la desproporción existente entre el esfuerzo en informarse políticamente y la influencia de su voto personal: "Solo los políticos profesionales y aquellos que valoran el conocimiento de los asuntos políticos por sí mismos poseen un incentivo para informarse con profundidad". Es por ello, más bien, un comportamiento racional por parte del votante: "Puesto que es casi seguro que un voto no será decisivo, incluso un votante preocupado de versa por el resultado carece virtualmente de incentivo alguno para investir demasiado en la adquisición del conocimiento suficiente para hacer una elección informada" (Somin, 2010, p. 259). En la misma línea, Joseph Femia (1996, p. 364) considera que la complejidad de las sociedades, y, por tanto, de la política hace imposible que el ciudadano común tenga la capacidad intelectual de afrontarla: "La misma complejidad alimenta la apatía, ya que la mayoría de la gente se da cuenta de que la participación política informada requeriría una enorme inversión de tiempo y energía, y que no marcaría diferencia alguna, dados los escondidos y, en su mayor parte, infiscalizables centros de poder".

No obstante, puede darse la vuelta al argumento y considerar que el debate político no conduce de manera necesaria a la confrontación y al atrincheramiento en las primeras posiciones. Es justo cuando se reprime la expresión política y se niega la voz a los afectados cuando más posibilidades existen de que pueda emerger la violencia o predominar la apatía.

Sin embargo, creemos que la opinión de Posner, Somin y Arias Maldonado (y otros en la misma línea) se basa en una concepción del individuo que tampoco es realista, 
por estática. Que alguien no esté informado, no significa que nunca lo sea. Es más, experimentos sociológicos como las ya mentadas encuestas deliberativas muestran bien a las claras lo contrario. A este respecto, los sondeos deliberativos de Fishkin y los numerosos mini-públicos ${ }^{3}$ que llevan organizándose desde hace años en diferentes países muestran que ciudadanos normales pueden convertirse en buenos deliberantes, independientemente de la complejidad de los asuntos que se traten. Incluso, como señala Dryzek (2010, p. 158), pueden ser mejores deliberantes que los políticos profesionales al menos en una dimensión: "La capacidad de reflexionar y cambiar de opinión como resultado de su participación en la deliberación".

Y a la inversa: que políticamente alguien se muestre apático no demuestra que lo será siempre. Quizá deberíamos preguntarnos, si aceptamos el argumento del desinterés habitual, por qué el ciudadano en las democracias liberales se siente generalmente fuera de la política (sin contar periódicas etapas de gran movilización y discusión). La responsabilidad, no sólo de los partidos y de los políticos profesionales, sino de los intermediarios privilegiados de la opinión pública, los medios de comunicación, aparece como clave para explicarlo. Si los medios no ejercen esa labor de comunicar las demandas y problematizaciones de la ciudadanía a las instituciones políticas, si más bien realizan una labor de encuadre informativo sesgado, que promueve la información interesada en sentido inverso, de arriba abajo, tampoco resulta extraño no sólo que la ciudadanía esté desinformada, sino que la que lo esté en alguna medida no encuentre interesante ni útil acercarse a los medios de comunicación para informarse o, si lo hace, sea con un cinismo nada constructivo.

Sobre esta supuesta "complejidad" de los asuntos políticos, Félix Ovejero (2008, p.175) afirma que es un argumento insuficiente para explicar el orillamiento de la participación ciudadana. Dicho argumento no sólo serviría para eliminar a los políticos de la toma de decisiones sino, que, además, no explica cómo, en realidad, la gente se conduce diariamente en sus vidas. La complejidad es para todos, pero lo característico de la civilización es que economiza la información que necesitamos para desenvolvernos en ella: "El avance y la sofisticación técnica han ido acompañados de un menor grado de exigencia de conocimiento de los usuarios acerca de los entresijos de su funcionamiento". Por no hablar de que incluso los políticos profesionales poco saben más allá de su reducido ámbito de conocimiento, que es lo que explica la existencia de los asesores y de la misma burocracia, por ejemplo.

Está fuera de las posibilidades de este artículo profundizar en la cooptación por los partidos políticos de instituciones públicas y de movimientos sociales, así como el cultivo de una idea de la política como tarea propia de una clase política por mor de una división del trabajo en la que se animaba al resto de la ciudadanía a dedicarse a sus asuntos privados en línea con una ideología consumista e individualista propia del sistema económico en que nos encontramos inmersos, por no hablar de la mala consideración que ha tenido siempre entre los políticos y los medios informativos

3 Siguiendo a Archon Fung (2003), los mini-públicos (mini-publics) son foros educativos que pretenden crear las condiciones ideales para que los ciudadanos formen, articulen y refinen sus opiniones sobre asuntos públicos. 
hasta la forma política más simple de expresión ciudadana que es la manifestación callejera, forma tradicional de acción de los movimientos sociales.

Por otro lado, y quizá como consecuencia de la crisis económica y de la percibida crisis de representatividad que se ha puesto de manifiesto con fenómenos sociales como el 15-M, el público en España parece bastante interesado en política, por cuanto, por ejemplo la eclosión de tertulias políticas no tiene parangón en el panorama mediático ni la cantidad de tiempo y espacio dedicado a ella, tanto en los medios públicos como en los privados, tanto en los tradicionales como en los que habitan en Internet. Por otro lado, como han demostrado las experiencias deliberativas, dichas actividades promueven el interés por los asuntos políticos, tanto por la confrontación de argumentos con otros interesados en los asuntos que le afecten como por la expectativa de que tanto su voz como su voto (en el caso de que lo haya) influyan y se tengan en cuenta. Las encuestas deliberativas, los foros ciudadanos y los mini-públicos, como señalamos antes, prueban que los ciudadanos sí se interesan por la política, sí se interesan por adquirir información y sí se muestran racionales cuando tienen la seguridad de que su voz se escuchará y su voto contará: "Si las instituciones están diseñadas para prescindir de su participación, es normal que no participe. Quien sabe que no le escuchan, no se molesta en hablar. No es egoísta, es simplemente sensato" (Ovejero, p. 184).

En cualquier caso, los índices de participación en las elecciones generales y en los escasos referéndums que en nuestro país han tenido lugar muestran a las claras que la mayoría de la ciudadanía sí participa, por no entrar en consideraciones sobre el significado político que para muchos posee la abstención, no siendo ésta necesariamente producto del mero desinterés.

En España, contando desde el período de la Transición hasta la actualidad, se han celebrado cuatro referéndums de carácter nacional: el del proyecto de ley para la reforma política (1976), que contó con la participación del $77^{\prime} 72 \%$ del censo; el de la aprobación del proyecto de Constitución (1978) tuvo una participación del 67,11\%; el de la permanencia en la OTAN (1986) alcanzó una participación del 59'42\%; y el del Tratado para una Constitución europea (2005) obtuvo un $41,77 \%{ }^{4}$. Respecto de los comicios a nivel nacional, la participación siempre ha superado, salvo en 4 ocasiones el 70\% del censo (1977, 78,83\%; 1979, 68,04\%; 1982, 79,97\%; 1986, $70,49 \%$; 1989, 69,74\%; 1993, 76,44\%; 1996, 77,38\%; 2000, 68,71\%; 2004, 75,66\%, 2008,73,85\%; 2011, 68,94\%; 2015, 73,20\%), por lo que sólo relajando mucho los límites del concepto puede hablarse de apatía, al menos, electoral. Las cifras de participación mucho más bajas se producen en las consultas al Parlamento Europeo (en las últimas tres elecciones se ha mantenido en torno al $45 \%$ ). Es posible, a modo de hipótesis, que la participación del ciudadano tenga relación con la percepción subjetiva de que su voto influye o tiene importancia en asuntos que considera que le atañen.

No obstante, Somin (1998, pp. 437-8) señala que una explicación consiste en lo que

4 Pueden consultarse los datos en la página web del Ministerio del Interior: http://www.infoelectoral.interior.es/min/home.html. (Consulta: 10 de febrero de 2016). 
se denomina "la paradoja del voto" (paradox of voting) por la que a) el votante puede sobrevalorar la importancia de su voto (lo que, por otro lado, se apresura a explicar no contradice el poco interés por adquirir información política dado el escaso valor del voto porque el grado de sobrevaloración del voto es suficiente para estimular las ganas de votar pero no lo bastante para invertir tiempo y esfuerzo en adquirir gran cantidad de información política); b) el voto tiene una capacidad "expresiva" o se emite por sentido del deber, pero, al igual que antes, no hasta tal punto que estimule el acopio importante de información; y c) la ignorancia política se expande por todas las clases sociales, culturas y niveles educativos. Somin siempre parece tener una explicación a mano cuando sus primeras teorías parecen rebatidas en la práctica. Así, si la población no es tan apática como debería entonces se deja guiar por la irracionalidad de las expectativas injustificadas o del deber o por necesidad de expresar su personalidad. La ciudadanía posee, a lo que se ve, la interesante virtud de no interesarse demasiado por la política en general pero sí lo suficiente por votar cuando se le llama a las urnas, reforzando así como epifenómeno de su apatía la legitimidad del sistema representativo.

Su opinión sobre la democracia deliberativa no puede por menos que ser presa también de su escepticismo de la capacidad y deseo de recopilar información de la ciudadanía. Dicho escepticismo se basa en que la necesidad que tiene la deliberación de que los ciudadanos no se limiten a expresar sus preferencias mediante el voto sino que deben fundamentarlas (reasonability) y estar abiertos transformarlas ante la recepción de nuevos argumentos (reciprocity) provoca que aquellos deban soportar una carga de conocimientos (knowledge burden) excesiva.

Cualquier concepto de democracia deliberativa que de manera simultánea pretenda mantener el control del votante sobre el gobierno y producir resultados políticos que difieran de modo significativo de los obtenidos en otras formas de democracia, impone de modo necesaria una carga cognitiva sustancial. Es por tanto lamentable que los demócratas deliberativos han pasado por alto generalmente la ignorancia ampliamente extendida que evita que la mayoría de los votantes no alcancen siquiera los niveles más modestos de conocimiento político que requieren las tradicionales concepciones pluralistas de control democrático. (Somin, 1998, p. 441)

La racionalidad del ciudadano se manifiesta en que es más beneficioso para él, dada la ínfima importancia de su voto, no realizar grandes esfuerzos (o ninguno) en adquirir conocimientos políticos. Es un problema clásico de la acción colectiva: el individuo se beneficiará de la distribución de un bien aunque no contribuya a él. Esta perspectiva racional explica la persistencia de dicha ignorancia a pesar de los avances educativos y de la mayor disponibilidad de la información. Sin embargo, Somin (2004, p. 14) extiende esta crítica a la elección de los líderes y de la elección de los partidos en los sistemas representativos. Además, relaciona el problema de la ignorancia del votante con el del poder de los grupos de interés, dado que aquél, incapaz de relacionar políticas y responsables, no será capaz de castigar, siquiera de modo retrospectivo, en las siguientes elecciones negándoles el voto. Sugiere, además que la deficiencia en el aprendizaje de la búsqueda de información política puede haber estado políticamente planeada: 
Si los votantes poseen escaso conocimiento de de la política, es probable que no sean conscientes de las actividades perjudiciales de grupos de interés, por lo que son incapaces de derribar a políticos que utilizan el poder del gobierno para beneficiar a aquellos a costa de los intereses públicos. Puede que exista un mecanismo causal en la dirección opuesta: del poder de los grupos de interés a la ignorancia política. Los lobbies pueden haber ayudado a perpetuar un sistema educativo que deficiente en la tarea de transmitir conocimiento político básico.

En su libro más reciente acerca de esta objeción, Ilya Somin (2013, p. 18) se decanta definitivamente por la racionalidad de la ignorancia del ciudadano media. La insignificancia del voto particular, su improbable capacidad de influir decisivamente en el resultado electoral o de cambiar cualesquiera políticas hacen poco atractivo el esfuerzo por adquirir información política. Por tanto, más que intentar que el ciudadano esté más informado, lo que habría que hacer es reducir al mínimo las consecuencias negativas de dicha ignorancia.

La ignorancia se vuelve un comportamiento racional incluso para aquellos que distan de ser idiotas y están preocupados de verdad por el bienestar de la nación. La insignificancia del voto particular en los resultados electorales hace que sea racional para la mayoría de los ciudadanos el dedicar poco esfuerzo a adquirir conocimientos políticos. Tienen poco incentivo, también, para esforzarse en analizar sin sesgos la información que poseen.

Por su lado, Sartori (1998, p. 6), eminente de defensor de la democracia representativa, y ácido crítico de los que él llama "directistas" (defensores de la democracia directa) se une a Platón en engrosar la lista de metáforas por las que se desprecia al pueblo en la participación directa del poder. En este caso, utiliza la metáfora del "cirujano", que correspondería a los políticos profesionales. Según él, la intención de los "directistas" es que el enfermo sustituya al cirujano. Por otro lado, se asiste también de la objeción de la ignorancia pública en su discurso en el Parlamento ante los diputados españoles:

La democracia representativa exige del ciudadano mucho menos que la directa y puede operar aunque su electorado sea mayoritariamente analfabeto (véase la India), incompetente o esté desinformado. Por el contrario, una democracia directa en tales circunstancias está condenada a la autodestrucción.

Como paliativo, sugiere que la única solución es mejorar la calidad de la opinión pública, si se quiere aumentar ("maximizar") la democracia. Cómo conseguirlo ya es otra cuestión, y dadas las escasas posibilidades de que eso se produzca a corto plazo, podríamos inferir que para Sartori y los demás defensores de la democracia representativa ésta es lo máximo que podemos conseguir.

Otra crítica de la democracia deliberativa, al menos tal y como la plantea Habermas, proviene de Matthew Weinshall (2003, p.28), quien atribuye al pensador germano, a partir de las tres condiciones de la situación ideal del habla, la exigencia de que los participantes en el discurso ideal "deben tener un conocimiento completo de los efectos esperados de la norma en cuestión en sus intereses" porque el principio de universalización que Habermas hace seguir de esas condiciones la implica. Weinshall hace de la información disponible el pivote sobre el que va a hacer girar su 
argumentación. Aunque la situación ideal no describe precisamente una situación real sino contrafáctica, Weinshall asegura que, para su formulación, Habermas se basa en consideraciones empíricas. Como Habermas relaciona su teoría del discurso con su propuesta de democracia deliberativa, Weinshall pretende refutar esta última señalando la supuesta inconsistencia de la noción de participante informado en el diálogo político.

Para Habermas, la deliberación tiene una doble justificación: una procedimental, por las condiciones de racionalidad e inclusividad; y otra por el resultado, que también será racional y que habrá tenido en cuenta los argumentos de todos los potencialmente afectados. Sin embargo, y ahí está el quid de la cuestión para Weinshall (2003, p. 32), en la vida diaria esto puede ser posible, pero en la esfera política, los asuntos son tan complejos que esto puede ponerse en duda: "Afirmar que un resultado instrumentalmente racional será producto del discurso o de la deliberación democráticos exige que uno asuma que el público o está muy bien informado o que es capaz de informarse de manera adecuada".

Abundando en la baja cualificación de público para juzgar y valorar asuntos políticos presente en la obra de Walter Lippmann y en un artículo de Philip Converse, Weinshall (2003, p. 42) señala la incapacidad del público para deliberar de manera racional sobre ellos, aunque sí sean más competentes para votar a un partido o apoyar a determinado líder político ${ }^{5}$. La falta de información del público afecta al modelo deliberativo de Habermas (y por extensión, añadimos, a todas las teorías democráticas deliberativas) porque este "exige que los ciudadanos deliberan sobre políticas particulares que afectan a sus intereses, o al menos acerca de cómo las personas elegidas debería determinar las políticas que afectarán a sus intereses" (Weinshall, 2003, p. 42). Weinshall llega a la conclusión, al igual que Somin, que las estrategias basadas en atajos cognitivos ya criticadas por Somin como las heurísticas basadas en la opinión de líderes políticos o mediáticos son insuficientes. Por ello, y ya que Habermas considera la democracia deliberativa como el mejor medio para producir políticas basadas en el principio de la universalización, la participación ciudadana, a causa de su ignorancia, no hace que las políticas resultantes sean más racionales: "A menos que se pueda mejorar el conocimiento político del público, Habermas no puede justificar la democracia deliberativa" (Weinshall, 2003, p. 53).

Por si lo anterior fuera poco, Weinshall señala, citando estudios de Zaller y Carpini, una relación entre nivel educativo y formativo y la adscripción a una ideología, por lo que si la ciudadanía estuviera (mejor) informada probablemente no dialogarían en aras del bien común, sino que se atrincherarían en posiciones de naturaleza dogmática ${ }^{6}$. En cambio, la relativa ignorancia facilita que se acepten opiniones ajenas:

5 Cf. CONVERSE, P.E. (2006): The nature of belief systems in mass publics (1964), Critical Review: $A$ Journal of Politics and Society, 18:1-3, 1-74

6 Cf. ZALLER, J.R. The Nature and Origin of Mass Opinion. New York: Cambridge University Press, 1992. y CARPINI DELLI, et al. What Americans Know About Politics and Why It Matters. New Haven: Yale University Press, 1996. 
Mientras la simplificación que produce la confianza en la ideología ayuda a los miembros de la élite cognitiva a formarse opiniones y organizar información acerca de muchos asuntos no relacionados, también elimina la necesidad de analizar independientemente los méritos de posiciones enfrentadas porque suministra un conjunto de creencias preestablecidas. El éxito del modelo de democracia deliberativa de Habermas requiere, no obstante, que los ciudadanos identifiquen los mejores argumentos llevando a cabo el tipo de análisis que la ideología anticipa. (Weinshall, 2003, p. 55)

Sin embargo, lo que estas concepciones anti-participativas soslayan habitualmente es la potencial mejora epistémica que implica la ampliación de la deliberación. Con la deliberación se aporta información, por lo que cabe deducir que cuantos más individuos (o, en su caso, representantes tanto políticos como de asociaciones) participen en la deliberación más probable es que se llegue a una decisión al menos mejor informada. Como dice Bernard Manin (1987, p. 351): "El proceso de deliberación, la confrontación de diferentes puntos de vista, ayuda a clarificar la información y a perfilar las propias preferencias. Pueden que lleguen, incluso, a modificar sus objetivos iniciales, si fuera necesario". Y un poco más adelante: "La deliberación tiende a incrementar la información y a identificar las preferencias. Ayuda a descubrir aspectos de las soluciones propuestas y de sus propios objetivos que no habían percibido antes" (Manin, 1987 p. 352). Como resume Seyla Benhabib (1996, p.71), ningún individuo en solitario puede anticipar y predecir todas las perspectivas posibles ni poseer toda la información potencialmente relevante para una decisión de alcance colectivo: "La deliberación es un procedimiento para estar informado".

En cualquier caso, parece dudoso refutar la democracia deliberativa aludiendo a la ignorancia de los presuntos deliberantes (y finalmente, votantes) pero no hacer lo mismo con la democracia representativa (lo que no es el caso de Somin, que critica ambas, pero sí el de Posner) pues si la ignara ciudadanía vota a representantes políticos como la sola acción política deseable, tampoco habría que esperar mucho de dichos representantes, pues podríamos preguntarnos sobre qué base habría que suponer que los votantes han votado con algún tipo de información y reflexión fiables. En esa línea, lan Budge (1996, p. 73) señala que muchos de los argumentos que se esgrimen contra la extensión de la participación ciudadana pueden convertirse de manera muy sencilla en argumentos contra la misma democracia representativa:

Los argumentos contra la democracia directa, particularmente en su forma no institucionalizada, tienen la costumbre de volverse en contra también de la democracia representativa, puesto que es difícil argumentar en contra de la implicación directa en política sin sembrar dudas sobre las capacidades políticas de los ciudadanos: La pregunta es entonces: si son los ciudadanos tan malos tomando decisiones, ¿por qué debería permitírseles decidir quién debe tomarlas?

Asimismo, es esa democracia representativa la que ha sido incapaz, al menos en España, de engendrar una ciudadanía informada y políticamente activa y de las correspondientes instituciones cívicas que la fomentaran, por lo que habría que dudar, y mucho, de la superioridad de la democracia representativa tal y como se ha 
institucionalizado, aunque sea la opción menos mala, con otras formas de democracia en su vertiente participativa-deliberativa.

Respecto del concepto mismo de ignorancia, Robert Talisse (2004, pp. 457-458) señala que puede entenderse por tal dos tipos principales: a) belief ignorance, que consistiría en la tenencia por un sujeto de falsas creencias, por lo que no puede llegar a conclusiones correctas. Sin embargo, si las creencias o premisas fueran ciertas, sus conclusiones sí que lo serían. Es decir, podría inferirse que el sujeto está mal informado; b) agent ignorance, que, por el contrario, consistiría en que el sujeto, pese a disponer de la información correcta, llegaría a conclusiones erróneas. Es decir, se trataría de un error cognitivo; en suma, de incompetencia. Talisse considera que si los cargos contra los ciudadanos en la teoría democrática deliberativa consisten en la ignorancia de tipo a) no resultan suficientes para refutarla, pero si se demostrara que consisten en la de tipo b), "Tales hallazgos serían devastadores para cualquier concepción de democracia, no sólo para la versión deliberativista" (Talisse, 2004, p. 461).

A fin de cuentas, lo que de manera implícita se desprende de las concepciones antiparticipativas y anti-deliberativas y, en consecuencia, elitistas, es la falta de respeto político por el ciudadano, que se basa en una profunda desconfianza hacia él. Nada habría de malo en ello, en el plano de la coherencia argumentativa, si se defendieran posturas filosóficas y políticas no democráticas, basadas más en un autoritarismo benigno o en una tecnocracia con un trasfondo antropológico que asuma la jerarquía como algo natural; pero defender la democracia (representativa) y pasar de contrabando concepciones anti-igualitarias resulta, al menos, contradictorio, porque la base de la democracia es la consideración de la igualdad política de los ciudadanos, si no su participación el gobierno o, al menos, su influencia en él. Igualdad que debería excluir, por principio, la consideración platónica de que unos están más capacitados que otros para gobernar y negar que otros tengan capacidad de ofrecer argumentos en los asuntos que, sobre todo, afecten a sus intereses.

Si se piensa que la autoridad política es algo que se ejercita por los ciudadanos de forma colectiva para promover y perseguir sus intereses comunes, entonces el fracaso en considerar a todos los ciudadanos como iguales en la posesión de esa autoridad es un asalto a la dignidad de aquellos excluidos. (Weale, 1999, p. 58)

Resulta sorprendente, en cierta medida, seguir leyendo en la filosofía política argumentos contra la supuesta tiranía de la mayoría, cuando, precisamente, lo que habría que temer es justo la tiranía de las élites (por definición, una minoría) que, excusándose en la ignorancia y el supuesto desinterés de la mayoría persigue objetivos no deseados por la mayoría, o que si los conociera, no los refrendaría. La manipulación de la esfera pública, la desactivación política de los actores de la sociedad civil, la promulgación de leyes que penalizan la expresión política son todas medidas encaminadas a ello.

A este respecto, Benjamin Barber (2003, p. 154) señala: "Imponen referéndums a la gente sin proporcionar información suficiente 0 debates extensos, sin impermeabilizarlos del dinero y las presiones de los medios de comunicación y después se mofan de ellos por su falta de juicio". 
Al fin y al cabo, como señalábamos al principio de este trabajo, la principal preocupación hasta la edad moderna en la filosofía política era cómo evitar la tiranía de los pocos, tal y como lo atestigua, entre otros, la obra de Aristóteles o la de Maquiavelo (2015, p. 50), quien ya dijo:

Y, sin duda, observando los propósitos de los nobles y de los plebeyos, veremos en aquéllos un gran deseo de dominar, y en éstos tan sólo el deseo de no ser dominados, y por consiguiente mayor voluntad de vivir libres, teniendo menos poder que los grandes para usurpar la libertad.

Esa preocupación también está presente en los constitucionalistas estadounidenses de hace tres siglos los antifederalistas, cuya preocupación era evitar, justo al contrario, la tiranía de la minoría. En nuestros días, esa preocupación se ha retomado recientemente en trabajos como Olygarchy, de Jeffrey Winters o Unequal Democracy, de Larry M. Bartels, ambos de Estados Unidos, país donde la desigualdad económica y la polarización social ha alcanzado niveles nunca vistos ${ }^{7}$ y que parecen prefigurar el escenario a medio plazo de los países de la Unión Europea.

No olvidemos, por último, que la participación en sentido fuerte significa no sólo que los ciudadanos oigan y se hagan oír, sino que el resultado final de la decisión esté relacionada con la opinión mayoritaria. Aspirar a conseguir esto sin una redistribución del poder político sólo puede promover la multiplicación de ritos de participación vacíos con los que los poseedores reales del poder obtienen algún grado de legitimación. "Citizen participation is a categorical term for citizen power", dijo Sherry Arnstein (1969). Y el poder, como la libertad, no se recibe como un regalo, sino que se conquista: por algo se llaman "conquistas democráticas" todo ese conjunto de derechos que protegen al ciudadano de la arbitrariedad del poder de los grandi de este mundo. La democracia es, en palabras de Barber (2003, p. 211), "ni gobierno de la mayoría ni mandato representativo: es autogobierno ciudadano. Sin ciudadanos, solo puede haber política de élites y de masas".

En definitiva, la objeción de la ignorancia del público es un argumento más de aquellos que desconfían profundamente de la ciudadanía, del pueblo gobernado, que, en ningún caso, querrían gobernante. Madison, Lippman, Ortega, Schumpeter y tantos otros hasta la actualidad representan una línea de argumentación teórica muy preocupada por evitar la tiranía de la mayoría, pero, quizá de una manera no tan paradójica, menos preocupada por evitar tiranías más minoritarias. Estamos de acuerdo con Seyla Benhabib (1996, p. 80) cuando afirma que la teoría democrática deliberativa

Trasciende la tradicional oposición entre una política de corte mayoritario contra otra de garantías liberales de derechos y libertades básicos, al punto que las condiciones normativas de los discursos, como el de los derechos y libertades básicos, deben ser vistas como reglas del juego que pueden ser contestadas dentro del juego, pero solo si se aceptan y se juega con ellas.

7 Cf. WINTERS, J. Olygarchy, New York: Cambridge University Press, 2011 y BARTELS, L.M. Unequal Democracy. The political economy of the new gilded age. New York: Russell Sage Foundation; Princeton and Oxford: Princeton University Press, 2008. 
Es, en resumidas cuentas, una falacia de falso dilema pretender que exista una oposición entre un régimen que proteja derechos y libertades individuales (representado por el liberalismo) y la democracia deliberativa y participativa, que, al parecer, daría vía libre a la tiranía de las mayorías y a la consiguiente pérdida de aquellos derechos y libertades. No por nada, llama la atención John Dryzek (2010, p. 5) respecto de

Esa larga y sombría historia de académicos que intentan demostrar que cualquier cosa por encima de una democracia liberal mínima demanda demasiado tiempo, energía y competencia de los ciudadanos corrientes, que, asimismo, están sujetos a todo tipo de paradojas y patologías.

La objeción de la ignorancia del público resulta útil para justificar un sistema elitista diseñado, como sugiere Lucas Ovejero (2008, p. 168), para desalentar la participación popular, y en el que "la ignorancia popular y el desinterés serían su natural combustible". No deja de ser una profecía autocumplida.

\section{Conclusión}

A pesar de que las teorías democráticas deliberativas-participativas han pasado de proponer una enmienda casi a la totalidad de los sistemas representativos liberales a buscar la manera de mejorar deliberativamente las instituciones de estos sistemas, ciertos teóricos se muestran contrarios a una mayor inclusión de la ciudadanía en el funcionamiento del sistema. La razón: la ignorancia, cuando no la apatía. En este artículo hemos hecho un breve recorrido por la tesis más conspicua de estos teóricos: la objeción de la ignorancia pública (Public Ignorance Objection). De fondo, está presente el temor a la tiranía de las mayorías, de tal modo que sólo procedimientos e instituciones representativas podrían frenar la supuesta irracionalidad de la mayoría de la ciudadanía. Sin embargo, hemos pretendido demostrar que la crítica a las teorías y procedimientos de la democracia deliberativa puede extenderse, sobre la base de sus argumentos, a la descalificación misma de la democracia liberal representativa. Por otro lado, sugerimos que la subestimación de la ciudadanía como agente político, así como la desincentivación para su participación, es conveniente para una concepción estrecha y elitista de la democracia por la que unos pocos gobiernan a la mayoría. 


\section{BIBLIOGRAFÍA}

ARIAS MALDONADO, M. (2007). La política en la teoría deliberativa. Notas sobre deliberación, decisión y conflicto. Revista Española de Ciencia Política. Núm. 16, págs. 37-59.

--- (2012). Deliberación y sociedad. En BELTRÁN, E. y VALLESPÍN, F. Deliberación pública y democracia contemporánea (pp. 75-84). Madrid: Síntesis.

ARNSTEIN, S. (1969). A Ladder Of Citizen Participation. Journal of the American Institute of Planners, 35:4, 216-224. Disponible en http://lithgow-schmidt.dk/sherryarnstein/ladder-of-citizen-participation.html.

BARBER, B. (2003). Strong Democracy. Participatory Politics for a New Age. Berkeley y Los Angeles: University of California Press.

BENHABIB, S. (1996). Toward a Deliberative Model of Democratic Legitimacy, en BENHABIB, S. (ed.). Democracy and Difference. Contesting the Boundaries of the Political (pp. 67-94). Princeton: Princeton University Press.

BOHAM, J. (1998). The Coming of Age of Deliberative Democracy. The Journal of Political Philosophy: Volume 6, Number 4, 400-425. Disponible en http://pages.uoregon.edu/koopman/courses_readings/phil123-

net/publicness/bohman_delib_dmcy.pdf.

BUDGE, I. (1996). The new challenge of direct democracy. Cambridge: Polity Press, 1996.

COHEN, J.L. (1999). Trust, voluntary association and workable democracy: the contemporary American discourse of civil society. En WARREN, M. (ed.), Democracy and Trust (pp. 208-248). Cambridge: Cambridge University Press, 1999.

DRYZEK, J.S. (2000). Deliberative Democracy and Beyond. Liberals, Critics, Contestations. New York: Oxford University Press.

--- (2010) Foundations and Frontiers of Deliberative Governance. Oxford: Oxford University Press.

FEMIA, J. (1996). Complexity and deliberative democracy. Inquiry: An Interdisciplinary Journal of Philosophy, 39:3-4, 359-397. DOI: $10.1080 / 00201749608602427$.

FUNG, A. (2003). Recipes for Public Spheres: Eight Institutional Design Choices and Their Consequences. Journal of Political Philosophy 11: 338-367. DOI: 10.1111/14679760.00181.

MANIN, B. (1987). On Legitimacy and Deliberation. Political Theory, Vol. 15, № 3, 338-368.

MAQUIAVELO, N (2015). Discursos sobre la primera década de Tito Livio. Madrid: Alianza, 3르 ed.

OVEJERO LUCAS, F. (2008). Cultura cívica, mercado y democracia liberal, en GARZÓN VALDÉS, MUGUERZA, J. y MURPHY, T.R. (comp.). Democracia y cultura política (pp. 165-202). Las Palmas de Gran Canaria: Fundación Mapfre Guanarteme. 
POSNER, R. (2004) Smooth Sailing. Legal Affairs. Disponible en Internet en http://www.legalaffairs.org/issues/January-February-

2004/feature_posner_janfeb04.msp.

SARTORI, G. (1998). En defensa de la representación política. Claves de Razón Práctica, № 91, p. 2-6 (6).

SHAPIRO, I. (2002) Optimal Deliberation? The Journal of Political Philosophy: Volume 10, Number 2, 196-211. DOI: 10.1111/1467-9760.00149.

SCHUMPETER, J.A. (1994). Capitalism, Socialism and Democracy. London and New York: Routledge, 1994.

SOMIN, I. (1998). Voter Ignorance and the democratic ideal. Critical Review: $A$ Journal of Politics and Society, 12:4, 413-458, DOI: 10.1080/08913819808443511.

--- (2004). Richard Posner's democratic pragmatism and the problem of ignorance, Critical Review: A Journal of Politics and Society, 16:1, 1-22. DOI: 10.1080/08913810408443596.

--- (2010) Deliberative Democracy and Political Ignorance, Critical Review, Vol. 22, Nos. 2-3, 253-79. DOI: 10.1080/08913811.2010.508635.

--- (2013). Democracy and Political ignorance: Why Smaller Government Is Smarter. Stanford: Stanford University Press.

SUNSTEIN, C. (2001). Designing Democracy. What Constitutions do. New York: Oxford University Press.

TALISSE, R.B. (2004). Does Public ignorance defeat Deliberative Democracy? Critical Review 16, № 4, 455-463. DOI: 10.1080/08913810408443619.

WEALE, A. (1999). Democracy. London: McMillan.

WEINSHALL, M. (2003). Means, ends and public ignorance in Habermas' theory of democracy, Critical Review: A Journal of Politics and Society, 15:1-2, 23-58. DOI: $10.1080 / 08913810308443573$. 